\title{
A Kinetic Study of the Radical-Scavenging Action of Tocotrienols in the Membranes of Egg Yolk Phosphatidylcholine Vesicles
}

\author{
Kenji FuKuZAWA $^{1}$, Aya OUCHI ${ }^{2}$, Shin-ichi NAGAOKA ${ }^{2}$, Akira SHIBATA ${ }^{1}$ and Kazuo MuKAI ${ }^{2}$ \\ ${ }^{1}$ Faculty of Pharmacy, Yasuda Women's University, Hiroshima 731-0153, Japan \\ ${ }^{2}$ Faculty of Science, Ehime University, Matsuyama 790-8577, Japan
}

(Received July 28, 2014)

\begin{abstract}
Summary Vitamin E is localized in membranes and functions as an efficient inhibitor of lipid peroxidation in biological systems. In this study, we measured the second-order rate constants $\left(k_{\mathrm{s}}\right)$ for the reaction of tocotrienol homologues $\left(\alpha-, \beta-, \gamma_{-}\right.$, and $\delta$-Toc-3Hs $)$ with the aroxyl radical (ArO·) used as a model for lipid peroxyl radicals (LOO·) in the membranes of egg yolk phosphatidylcholine (EYPC) vesicles by stopped-flow spectrophotometry, and compared them to those of tocopherol homologues $(\alpha-, \beta-, \gamma-$, and $\delta$-TocHs). The relative rate constants of Toc-3H homologues to $\alpha$-Toc-3H in membranes $(\alpha / \beta / \gamma /$ $\delta=100 / 83.7 / 63.2 / 20.2$ ) were not much different to those of TocH homologues to $\alpha$-TocH $(\alpha / \beta / \gamma / \delta=100 / 88.4 / 83.8 / 17.3)$. Each $k_{\mathrm{s}}$ value of Toc-3H homologues in membranes was $60-80 \%$ of that of the corresponding TocH homologues except for the almost identical $k_{\mathrm{S}}$ values of $\delta$-homologues, but there was no difference in EtOH solution between each $k_{\mathrm{s}}$ value of the corresponding homologues of Toc- $3 \mathrm{H}$ and TocH. These results indicate that the difference of the alkyl-side chain structure of vitamin E causes a change in the mobility of vitamin E molecules and/or the location of their antioxidant $\mathrm{OH}$-groups in membranes, resulting in lowered radical-trapping rates of Toc-3Hs. By use of the ratio of the $k_{\text {inh }}$ value of $\alpha$-TocH with LOO $\left(3.20 \times 10^{6} \mathrm{M}^{-1} \mathrm{~s}^{-1}\right)$ to the $k_{\mathrm{s}}$ value of $\alpha$-TocH with $\mathrm{ArO} \cdot\left(8.05 \times 10^{4} \mathrm{M}^{-1} \mathrm{~s}^{-1}\right)$ in chlorobenzene (that is, 39.8), the $k_{\text {inh }}$ value for the reaction of $\alpha$-TocH with LOO in membrane was estimated to be $1.03 \times 10^{5} \mathrm{M}^{-1} \mathrm{~s}^{-1}$.
\end{abstract}

Key Words vitamin E, tocopherol, tocotrienol, antioxidant, membrane

Vitamin E is a generic term for all tocopherol (TocH) and tocotrienol (Toc-3H) homologues. The antioxidant effect of vitamin $\mathrm{E}$ has been ascribed to the oxidation of its phenolic hydroxyl group by lipid peroxyl radicals (LOO·), producing corresponding tocopheroxyl radicals (Toc·) or tocotrienoxy radicals (Toc-3·) (reaction 1 ). The mechanism involved has been studied extensively by several investigators (1-5).

$$
\mathrm{LOO} \cdot+\mathrm{TocH}(\mathrm{Toc}-3 \mathrm{H}) \stackrel{k_{\text {inh }}}{\longrightarrow} \mathrm{LOOH}+\mathrm{Toc} \cdot(\text { Toc-3 } \cdot) \text { (1) }
$$

It is well known that lipophilic vitamin $\mathrm{E}$ is localized in biomembranes and functions as an efficient inhibitor of lipid peroxidation in membranes $(6-10)$. We recently reported the second-order rate constants $\left(k_{\mathrm{s}}\right)$ for the reactions of $\alpha-, \beta-, \gamma-, \delta$-TocH, and tocol with the 2,6-di$t$-butyl-4-(4-methoxyphenyl)phenoxyl radical (ArO-), which can be regarded as a model for lipid peroxyl radicals (LOO·), in membranes (reaction 2) using stoppedflow spectrophotometry (10).

$$
\mathrm{ArO} \cdot+\mathrm{TocH}(\mathrm{Toc}-3 \mathrm{H}) \stackrel{k_{\mathrm{s}}}{\longrightarrow} \mathrm{ArOH}+\mathrm{Toc} \cdot(\mathrm{Toc}-3 \cdot)
$$

In this experiment, we used samples of egg yolk phosphatidylcholine (EYPC) vesicles as a membrane model in a $70 \%$ methanol solution with low turbidity, which is suitable for measuring by spectrophotometry. In the

E-mail: fukuzawaknj@gmail.com present work, we measured $k_{\mathrm{s}}$ values in EYPC membranes for the reactions of $\alpha-, \beta-, \gamma$, and $\delta$-Toc-3Hs with the ArO radical.

\section{Experimental Procedures}

The $\alpha-, \beta-, \quad \gamma-, \delta$-tocotrienols and $\alpha$-tocopherols were kindly supplied by Eisai Food \& Chemical Co., Ltd. (Tokyo, Japan). Egg yolk phosphatidylcholine (EYPC) was obtained from Nippon Oil and Fat Co. (Tokyo, Japan). The aroxyl radical (ArO·) was synthesized as previously reported (11).

EYPC vesicles used as a membrane model were prepared in $70 \% \mathrm{MeOH}\left(\mathrm{MeOH}: \mathrm{H}_{2} \mathrm{O}=7: 3\right.$, vol/vol), because samples with low turbidity that maintain the membrane structure are suitable for the measurement of spectra (10). We prepared a 70\% $\mathrm{MeOH}$ solution of ArO just before measurement by stopped-flow spectrophotometry. The ratio of $\alpha$-TocH to phospholipids in biological membranes is reported to be 1 : 1,000-2,000 (12). In the present work, measurements of the rate constants $\left(k_{\mathrm{s}}\right)$ were performed using membranes for which the ratios of Toc-3H to EYPC were $1: 100-500$, because the lower ratio of phospholipid to antioxidant produced a sample solution with the lower turbidity suitable for spectrophotometry.

The kinetic data were obtained with a Unisoku Model RS-450 stopped-flow spectrophotometer by mixing 

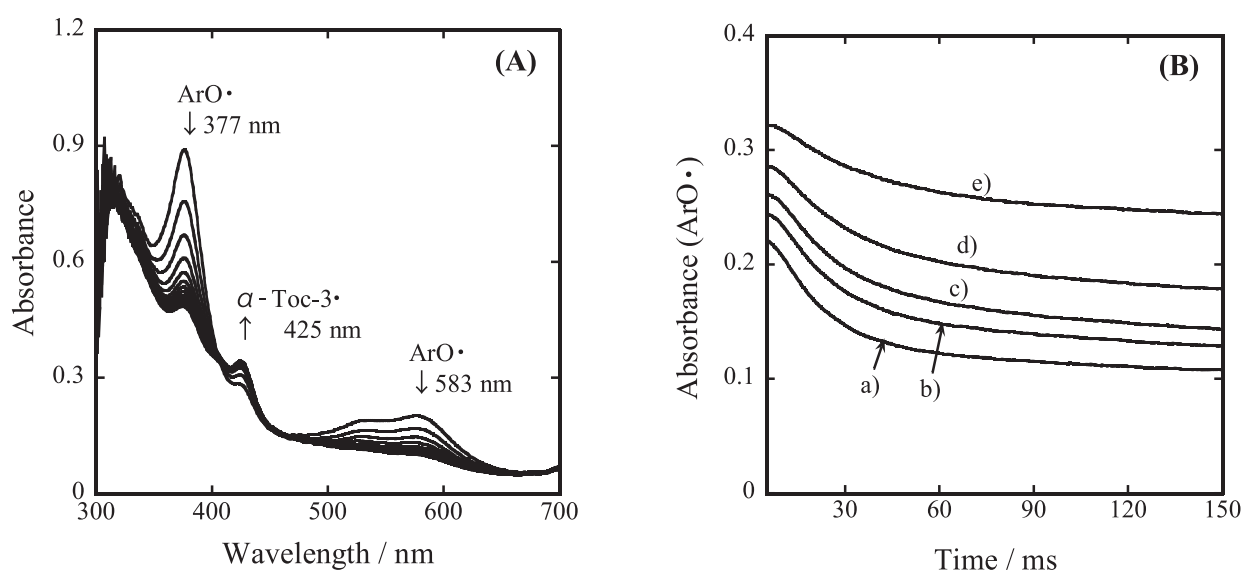

Fig. 1. (A) Changes in the electronic absorption spectra of $\mathrm{ArO} \cdot$ and $\alpha$-Toc-3 $\cdot$ during the reaction of $\mathrm{ArO} \cdot$ with $\alpha$-Toc-3H in $10 \mathrm{~mm}$ EYPC vesicles in $70 \% \mathrm{MeOH}$ solution at $25^{\circ} \mathrm{C}$. The spectra were recorded at $8 \mathrm{~ms}$ intervals. The arrow indicates a decrease in the absorbance of ArO and an increase in the absorbance of $\alpha$-Toc-3 $\cdot[\text { ArO }]_{t=0}=\sim 7.0 \times 10^{-5} \mathrm{M}$ and $[\alpha-\mathrm{TocH}]_{t=0}=1.27 \times 10^{-4}$ M. (B) Time courses of the decrease of absorption at $583 \mathrm{~nm}$ associated with the decay of ArO during the reaction of ArO with $\alpha$-Toc-3H in $10 \mathrm{~mm} \mathrm{EYPC}$ vesicles in $70 \% \mathrm{MeOH}$ solution at $25^{\circ} \mathrm{C}$. Concentrations of $\alpha$-Toc- $3 \mathrm{H}$ were (a) $1.27 \times 10^{-4} \mathrm{M}$, (b) $1.02 \times 10^{-4} \mathrm{M}$, (c) $7.63 \times 10^{-5} \mathrm{M}$, (d) $5.09 \times 10^{-5} \mathrm{M}$, (e) $2.54 \times 10^{-5} \mathrm{M}$. $[\mathrm{ArO} \cdot]_{\mathrm{t}=0}=\sim 7.0 \times 10^{-5} \mathrm{M}$.

equal volumes of $70 \% \mathrm{MeOH}$ solutions of (A) $0.1 \mathrm{~mm}$ ArO• and (B) 20 mM EYPC vesicles containing vitamin E under a nitrogen atmosphere.

The time between mixing the two solutions and recording the first data point (that is, dead time) was 10-20 ms. The reaction was monitored by either single wavelength detection or a photo-diode array detector attached to the stopped-flow spectrophotometer. All measurements were performed at $25.0 \pm 0.5^{\circ} \mathrm{C}$. Experimental errors in the rate constants $\left(k_{\mathrm{s}}\right)$ are estimated to be about $5 \%$ and $8 \%$ in chlorobenzene and vesicle solutions, respectively.

\section{Results and Discussion}

The changes in the absorption spectrum measured during the reaction of $\alpha$-Toc-3H with ArO (Eq. (3)) are shown in Fig. 1A. When a 70\% $\mathrm{MeOH}$ solution of $\alpha$-TocH with EYPC vesicles was added to a $70 \% \mathrm{MeOH}$ solution of $\mathrm{ArO} \cdot$, the $\mathrm{ArO} \cdot$ absorption peak disappeared immediately, the $\alpha$-Toc-3 $\cdot$ peak appeared, and the isosbestic points were observed. As shown in Fig. 1B, after about $5 \mathrm{~ms}$ lag time probably due to penetration of $\mathrm{ArO}$. into membranes of EYPC vesicles, the decay of absorbance of $\mathrm{ArO} \cdot($ at $583 \mathrm{~nm}$ ) was observed.

The pseudo-first-order rate constants $\left(k_{\text {obsd }}\right)$ were determined by evaluating the decrease in the absorbance of the ArO by the reaction with various concentrations of $\alpha$-Toc-3H. As shown in Fig. 2, the $k_{\text {obsd }}$ of ArO at $583 \mathrm{~nm}$ plotted against $\alpha$-Toc-3H concentrations was linearly dependent on the $\alpha$-Toc-3H concentration, and thus the rate equation was expressed as

$$
\begin{aligned}
-\mathrm{d}[\mathrm{ArO} \cdot] / \mathrm{d} t & =k_{\mathrm{obsd}}[\mathrm{ArO} \cdot] \\
& =k_{\mathrm{s}}[\alpha-\mathrm{Toc}-3 \mathrm{H}][\mathrm{ArO} \cdot]
\end{aligned}
$$

where $k_{\mathrm{s}}$ is the second-order rate constant for oxidation of $\alpha$-TocH by ArO . Similar measurements were performed for $\beta$-, $\gamma$-, and $\delta$-Toc-3Hs (Fig. 2).

We calculated their membranous second-order rate

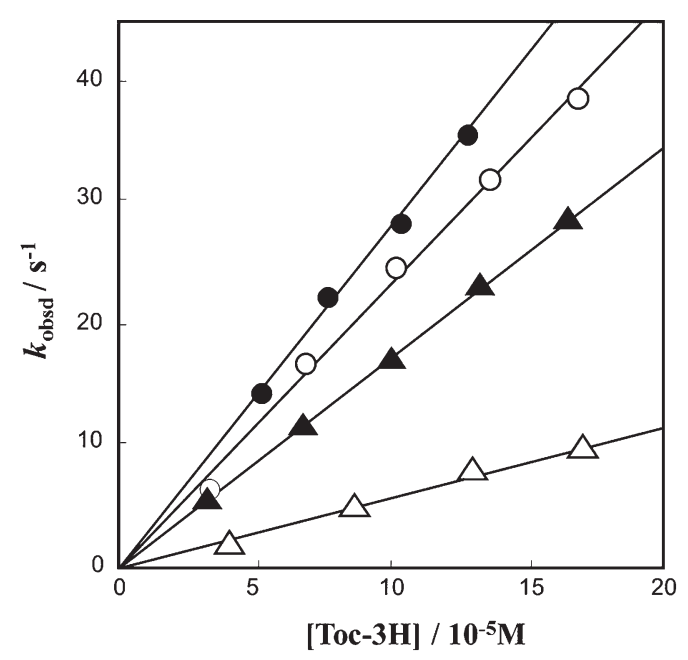

Fig. 2. Dependence of pseudo-first-order rate constant $\left(k_{\text {obsd }}\right)$ values on concentration of Toc-3H homologues in $10 \mathrm{mM} \mathrm{EYPC}$ vesicles in $70 \% \mathrm{MeOH}$ solution at $25^{\circ} \mathrm{C}$. The $k_{\text {obsd }}$ values of $\alpha$-Toc-3H were obtained by analyzing the decrease in the absorbance of $\mathrm{ArO} \cdot$ at $583 \mathrm{~nm}$, as shown in Fig. 1B. The $k_{\text {obsd }}$ values of the other Toc$3 \mathrm{H}$ homologues were obtained from the time courses of the decrease of absorption at $583 \mathrm{~nm}$ associated with the decay of ArO during the reaction with Toc-3H homologues (data not shown). ๑, $\alpha$-Toc-3H; $\bigcirc, \beta$-Toc3H; $\boldsymbol{\Delta}, \gamma$-Toc-3H; $\triangle, \delta$-Toc-3H.

constant $\left(k_{\mathrm{s}}\right)$ assuming that all antioxidant molecules were located in EYPC membranes and using the estimation that their concentration in EYPC membranes (mol of Toc-3H or TocH/L of EYPC) was 133 times higher in the bulk $\mathrm{MeOH} / \mathrm{H}_{2} \mathrm{O}$ phase (13). The $k_{\mathrm{s}}$ values of Toc-3H and TocH homologues obtained in EYPC membrane and in EtOH solution are summarized in Table 1 . The $k_{\mathrm{s}}$ values of Toc-3H and TocH homologues 
Table 1. Second-order rate constants $\left(k_{\mathrm{s}}\right)$ for reaction of ArO with Toc-3Hs and TocHs in EYPC vesicles and EtOH.

\begin{tabular}{|c|c|c|c|c|c|c|}
\hline & \multicolumn{2}{|c|}{$\begin{array}{l}\text { EYPC vesicle (observed) } \\
\qquad k_{\mathrm{s}}\left(\mathrm{M}^{-1} \mathrm{~S}^{-1}\right)\end{array}$} & \multicolumn{2}{|c|}{$\begin{array}{l}\text { EYPC vesicle (corrected })^{1} \\
\qquad k_{\mathrm{s}}\left(\mathrm{M}^{-1} \mathrm{~S}^{-1}\right)\end{array}$} & \multicolumn{2}{|c|}{$\begin{array}{c}\mathrm{EtOH} \\
k_{\mathrm{s}}\left(\mathrm{M}^{-1} \mathrm{~s}^{-1}\right)\end{array}$} \\
\hline & Toc-3H & $\mathrm{TocH}^{2}$ & Toc-3H & $\mathrm{TocH}^{2}$ & Toc- $3 \mathrm{H}^{3}$ & $\mathrm{TocH}^{2,3}$ \\
\hline$\alpha$-Form & $2.78 \times 10^{5}$ & $3.45 \times 10^{5}$ & $2.09 \times 10^{3}$ & $2.59 \times 10^{3}$ & $4.97 \times 10^{3}$ & $5.12 \times 10^{3}$ \\
\hline$\beta$-Form & $2.33 \times 10^{5}$ & $3.04 \times 10^{5}$ & $1.75 \times 10^{3}$ & $2.29 \times 10^{3}$ & $3.04 \times 10^{3}$ & $2.77 \times 10^{3}$ \\
\hline$\gamma$-Form & $1.75 \times 10^{5}$ & $2.88 \times 10^{5}$ & $1.32 \times 10^{3}$ & $2.17 \times 10^{3}$ & $2.76 \times 10^{3}$ & $2.82 \times 10^{3}$ \\
\hline$\delta$-Form & $5.63 \times 10^{4}$ & $5.95 \times 10^{4}$ & $4.23 \times 10^{2}$ & $4.48 \times 10^{2}$ & $1.09 \times 10^{3}$ & $1.02 \times 10^{3}$ \\
\hline
\end{tabular}

${ }^{1}$ Corrected $k_{\mathrm{s}}$ values were calculated by adjusted concentrations of Toc-3H and TocH in membranes (assumed to be 133 times concentrated) (13).

${ }^{2} k_{\mathrm{S}}$ values reported in Ref. (10).

${ }^{3} k_{\mathrm{s}}$ values reported in Ref. (16).

Table 2. Relative rate constants $\left(k_{s}\right)$ for reaction of ArO $\cdot$ with Toc-3Hs and TocHs $\left(100 k_{\mathrm{s}}(\mathrm{Toc}-3 \mathrm{H}) / k_{\mathrm{s}}(\alpha-\mathrm{Toc}-3 \mathrm{H})\right.$ and $100 k_{\mathrm{s}}$ $\left.(\mathrm{TocH}) / k_{\mathrm{s}}(\alpha-\mathrm{TocH})\right)$, and comparison of rate constants between each analogue of Toc-3H and TocH $\left(100 k_{\mathrm{s}}(\mathrm{Toc}-3 \mathrm{H}) /\right.$ $\left.k_{\mathrm{S}}(\mathrm{TocH})\right)$ in EYPC vesicles and EtOH.

\begin{tabular}{|c|c|c|c|c|c|c|}
\hline & \multicolumn{2}{|c|}{ EYPC vesicle } & \multicolumn{2}{|c|}{$\mathrm{EtOH}$} & \multicolumn{2}{|c|}{$\begin{array}{c}100 k_{\mathrm{s}}(\mathrm{Toc}-3 \mathrm{H}) \\
\quad / k_{\mathrm{s}}(\mathrm{TocH})\end{array}$} \\
\hline & $\begin{array}{c}100 k_{\mathrm{s}}(\text { Toc-3H }) \\
/ k_{\mathrm{s}}(\alpha-\text { Toc-3H })\end{array}$ & $\begin{array}{c}100 k_{\mathrm{S}}(\mathrm{TocH}) \\
/ k_{\mathrm{S}}(\alpha-\mathrm{TocH})\end{array}$ & $\begin{array}{l}100 k_{\mathrm{s}}(\text { Toc-3H }) \\
/ k_{\mathrm{s}}(\alpha-\text { Toc-3H })\end{array}$ & $\begin{array}{c}100 k_{\mathrm{s}}(\mathrm{TocH}) \\
/ k_{\mathrm{S}}(\alpha-\mathrm{TocH})\end{array}$ & EYPC vesicle & $\mathrm{EtOH}$ \\
\hline$\alpha$-Form & 100 & 100 & 100 & 100 & 80.6 & 97.1 \\
\hline$\beta$-Form & 83.7 & 88.4 & 61.2 & 54.1 & 76.6 & 109.7 \\
\hline$\gamma$-Form & 63.2 & 83.8 & 55.5 & 55.1 & 60.8 & 97.9 \\
\hline$\delta$-Form & 20.2 & 17.3 & 21.9 & 19.9 & 94.6 & 106.9 \\
\hline
\end{tabular}

Table 3. Second-order rate constants ( $k_{\mathrm{s}}$ and $k_{\mathrm{inh}}$ ) for reaction of ArO and LOO with $\alpha$-TocH (and $\alpha$-Toc-3H) in chlorobenzene (and EYPC vesicles), respectively.

\begin{tabular}{|c|c|c|c|c|c|}
\hline & \multicolumn{2}{|c|}{ Chlorobenzene } & \multirow{2}{*}{$\begin{array}{c}k_{\text {inh }}(\mathrm{LOO} \cdot) \\
/ k_{\mathrm{s}}(\mathrm{ArO} \cdot)\end{array}$} & \multicolumn{2}{|c|}{ EYPC vesicle } \\
\hline & $\begin{array}{l}k_{\mathrm{s}}(\mathrm{ArO} \cdot) \\
\left(\mathrm{M}^{-1} \mathrm{~s}^{-1}\right)\end{array}$ & $\begin{array}{c}k_{\text {inh }}(\mathrm{LOO} \cdot) \\
\left(\mathrm{M}^{-1} \mathrm{~s}^{-1}\right)\end{array}$ & & $\begin{array}{l}k_{\mathrm{s}}(\mathrm{ArO} \cdot) \\
\left(\mathrm{M}^{-1} \mathrm{~s}^{-1}\right)\end{array}$ & $\begin{array}{c}k_{\text {inh }}(\mathrm{LOO} \cdot) \\
\left(\mathrm{M}^{-1} \mathrm{~s}^{-1}\right)\end{array}$ \\
\hline & $8.05 \times 10^{4}(\text { observed })^{1}$ & $3.20 \times 10^{6}(\text { rep orted })^{2}$ & 39.8 & $2.59 \times 10^{3}(\text { observed })^{1}$ & $1.03 \times 10^{5}(\text { estimated })^{3}$ \\
\hline$\alpha$-Toc- $3 \mathrm{H}$ & $8.09 \times 10^{4}(\text { observed })^{1}$ & $3.22 \times 10^{6}(\text { estimated })^{3}$ & 39.8 & $2.09 \times 10^{3}(\text { observed })^{1}$ & $8.31 \times 10^{4}(\text { estimated })^{3}$ \\
\hline
\end{tabular}

\footnotetext{
${ }^{1} k_{\mathrm{S}}$ values measured by this experiment.

${ }^{2} k_{\mathrm{s}}$ values reported in Ref. (1).

${ }^{3} k_{\mathrm{S}}$ values estimated by using the value of the ratio $\left(k_{\mathrm{inh}}(\mathrm{LOO} \cdot) / k_{\mathrm{s}}(\mathrm{ArO} \cdot)=39.8\right)($ see text $)$.
}

in membrane were about half of those in EtOH solution. The $k_{\mathrm{s}}$ values of Toc- $3 \mathrm{H}$ homologues in membrane increased in the order of $\delta$-Toc- $3 \mathrm{H}<\gamma$-Toc- $3 \mathrm{H}<\beta$-Toc$3 \mathrm{H}<\alpha$-Toc-3H. This order was same as that of the $k_{\mathrm{s}}$ values of $\mathrm{ToH}$ homologues in membrane reported recently by us (10). Furthermore, the relative reaction rate constants of Toc-3H analogues to $\alpha$-Toc-3H in membrane $(\alpha / \beta / \gamma / \delta=100 / 83.7 / 63.2 / 20.2)$ were not much different to those of the reaction rate constants of TocH homologues to $\alpha$-TocH in membrane $(\alpha / \beta / \gamma /$ $\delta=100 / 88.4 / 83.8 / 17.3$ ) (Table 2), indicating that the relative radical trapping activities of Toc- $3 \mathrm{H}$ homologues in membrane are almost the same as those of
TocH homologues.

Yoshida et al. (14) reported that the reactivities of $\alpha$, $\beta-, \gamma$, and $\delta$-Toc-3Hs toward peroxyl radicals are the same as those of the corresponding $\alpha_{-}^{-}, \beta-, \gamma_{-}$, and $\delta$-Toc$3 \mathrm{H}$ homologues in acetonitrile solution. On the other hand, Servinova et al. (15) reported that $\alpha$-Toc-3H has more potent antioxidant activity than $\alpha$-TocH for lipid peroxidation in rat liver microsomal membranes. In the present work, each $k_{\mathrm{s}}$ value of Toc-3H homologues in membranes was $60-80 \%$ of that of the corresponding TocH homologue except for the nearly identical $k_{\mathrm{s}}$ values of $\delta$-homologues, although there was no difference in EtOH solution between each $k_{\mathrm{s}}$ value of corresponding 
homologues of Toc-3H and TocH (16) (Table 2). These results indicate that the difference in the alkyl side chain structure of vitamin E causes the change in the mobility of vitamin E molecules and/or the location of their antioxidant $\mathrm{OH}$-groups in membranes, resulting in the lowered radical-trapping rate of Toc- $3 \mathrm{H}$.

Next, we tried to evaluate the $k_{\text {inh }}$ value for the reaction of $\alpha$-TocH with LOO in membrane, by assuming that the ratio of the $k_{\text {inh }}$ value of $\alpha$-TocH with LOO to the $k_{\mathrm{s}}$ value with $\mathrm{ArO} \cdot$ in solvent is the same as their ratio $\left(k_{\mathrm{inh}} / k_{\mathrm{s}}\right)$ in membranes. We previously reported that the $k_{\mathrm{s}}$ value of $\alpha$-TocH was dependent on the polarity of the solvents and increased with a decrease in the polarity of solvent (4).

In fact, the $k_{\mathrm{s}}$ values $\left(8.09 \times 10^{4}\right.$ and $\left.8.05 \times 10^{4} \mathrm{M}^{-1} \mathrm{~s}^{-1}\right)$ obtained for $\alpha$-Toc-3H and $\alpha$-TocH in chlorobenzene were larger than the corresponding ones $\left(4.97 \times 10^{3}\right.$ and $5.12 \times 10^{3} \mathrm{M}^{-1} \mathrm{~s}^{-1}$ ) in EtOH with higher polarity (see Table 3$)$. Since the $k_{\text {inh }}$ value of $\alpha$-TocH in chlorobenzene was reported to be $3.20 \times 10^{6} \mathrm{M}^{-1} \mathrm{~s}^{-1}$ (1), we compared this $k_{\text {inh }}$ value to the $k_{\mathrm{s}}$ value $\left(8.05 \times 10^{4} \mathrm{M}^{-1} \mathrm{~s}^{-1}\right)$ of $\alpha$-TocH in chlorobenzene.

By use of the value of the ratio $\left(k_{\text {inh }}(\mathrm{LOO} \cdot) / k_{\mathrm{s}}\right.$ $(\mathrm{ArO} \cdot)=39.8)$ in chlorobenzene, the $k_{\text {inh }}$ value of $\alpha$-TocH in membrane was tentatively estimated to be $1.03 \times 10^{5} \mathrm{M}^{-1} \mathrm{~s}^{-1}\left(=39.8 \times 2.59 \times 10^{3} \mathrm{M}^{-1} \mathrm{~s}^{-1}\right)$, where $2.59 \times 10^{3} \mathrm{M}^{-1} \mathrm{~s}^{-1}$ is the $k_{\mathrm{s}}$ value for reaction of $\alpha$-TocH with $\mathrm{ArO} \cdot$ in membranes (see Table 3 ). The $k_{\text {inh }}$ value $\left(1.03 \times 10^{5} \mathrm{M}^{-1} \mathrm{~s}^{-1}\right)$ estimated was about twice the $k_{\mathrm{inh}}$ value in 1-palmitoyl-2-linoleoylphosphatidylcholine membranes $\left(4.7 \times 10^{4} \mathrm{M}^{-1} \mathrm{~S}^{-1}\right)$ reported by Barclay et al. (7), suggesting higher mobility of EYPC molecules in membranes prepared in $70 \% \mathrm{MeOH}$ solution.

\section{Acknowledgments}

We thank Eisai Food \& Chemical Co., Ltd. for the generous gifts of $\alpha-, \beta-, \gamma-$, and $\delta$-tocotorienols and $\alpha$-tocopherol.

\section{REFERENCES}

1) Burton GW, Doba T, Gabe EJ, Hughes L, Lee FL, Prasad L, Ingold KU. 1985. Autoxidation of biological molecules. 4. Maximizing the antioxidant activity of phenols. J Am Chem Soc 107: 7053-7065.

2) Barclay LRC. 1993. Model biomembranes: Quantitative studies of peroxidation, antioxidant action, partitioning, and oxidative stress. Can J Chem 71: 1-16.

3) Yoshida Y, Saito Y, Jones LS, Shigeri Y. 2007. Chemical reactivities and physical effect in comparison between tocopherols and tocitrienols: Physiological significance and prospects as antioxidants. J Biosci Bioengineer 104: $439-445$.

4) Mukai K, Ouchi A, Mitarai A, Ohara K, Matsuoka C. 2009. Formation and decay dynamics of vitamin E radical in the antioxidant reaction of vitamin E. Bull Chem Soc Jpn 82: 494-503.

5) Niki E. 2010. Assessment of antioxidant capacity in vitro and in vivo. Free Radic Biol Med 49: 503-515.

6) Suzuki YJ, Tsuchiya M, Wassall SR, Choo YM, Govil G, Kagan VE, Packer L. 1993. Structure and dynamic membrane properties of $\alpha$-tocopherol and $\alpha$-tocotrienol: Implication to the molecular mechanism of their antioxidant potency. Biochemistry 32: 10692-10699.

7) Barclay LRC, Vinqvist MR, Antunes F, Pinto RE. 1997. Antioxidant activity of vitamin $\mathrm{E}$ determined in a phospholipid membrane by product studies: Avoiding chain transfer reaction by vitamin E radicals. J Am Chem Soc 119: $5764-5765$.

8) Atkinson J, Epand RF, Epand RM. 2008. Tocopherols and tocotrienols in membranes: A critical review. Free Radic Biol Med 44: 739-764.

9) Fukuzawa K. 2008. Dynamics of lipid peroxidation and antioxidation of $\alpha$-tocopherol in membranes. J Nutr Sci Vitaminol 54: 273-285.

10) Fukuzawa K, Ouchi A, Shibata A, Nagaoka S, Mukai K. 2011. Kinetic study of aroxyl radical-scavenging action of vitamin $\mathrm{E}$ in membranes of egg yolk phosphatidylcholine vesicles. Chem Phys Lipids 164: 205-210.

11) Rieker A, Scheffler K. 1965. Die beteiligung von phenylresten an der aroxylmesomerie. Liebigs Ann Chem 689: 78-91.

12) Gruger EH Jr, Tappel AL. 1971. Reactions of biological antioxidants III. Composition of biological membranes. Lipids 6: 147-148.

13) Fukuzawa K, Matsuura K, Tokumura A, Suzuki A, Terao J. 1997. Kinetics and dynamics of singlet oxygen scavenging by $\alpha$-tocopherol in phospholipid model membranes. Free Radic Biol Med 22: 923-930.

14) Yoshida Y, Niki E, Noguchi N. 2003. Comparative study on the action of tocopherols and tocotrienols as antioxidant: Chemical and physical effects. Chem Phys Lipids 123: $63-75$.

15) Servinova E, Kagan V, Han D, Packer L. 1991. Free radical recycling and intramembrane mobility in the antioxidant properties of $\alpha$-tocopherol and $\alpha$-tocotrienol. Free Radic Biol Med 10: 263-275.

16) Ouchi A, Nagaoka S, Suzuki T, Izumisawa K, Koike T, Mukai K. 2014. Finding of synergistic and cancel effects on the aroxyl radical-scavenging rate and suppression of prooxidant effect under the coexistence of $\alpha$-tocopherol and $\beta-, \gamma$-, and $\delta$-tocopherols (or -tocotrienols). J Agric Food Chem 62: 8101-8113. 